\title{
Intra-Rural Fertility Determinants in Zimbabwe: A Path Analysis ${ }^{1}$
}

\author{
http://aps.journals.ac.za
}

Thando D. Gwebu

Department of Environmental Science

University of Botswana

Gaborone, BOTSWANA

\begin{abstract}
Studies on spatial fertility differentials in sub-Sahara Africa normally treat the rural sector as a single and uniform geographical entity. This approach, unfortunately, tends to mask differences, which may exist between components of the rural sub-sectors. This empirical study, based on both quantitative analyses and participatory methodologies, has stratified one rural district in southwestern Zimbabwe, into communal lands and resettlement schemes, in order to investigate the fertility differentials at intra-rural levels. The working hypothesis is that because the respective rural sub-areas differ in their levels of socioeconomic development, the relative impacts of the determinants of fertility should reflect these differences. Data on fertility patterns and their correlates were extracted from 1,542 married mothers, within the ages of 15-49, in the rural district. 832 of these were from the resettlement areas and 710 were selected from communal lands. Results from a descriptive bivariate model confirmed that resettlement areas have higher fertility than the communal lands. The present study utilizes path analysis, which is considered appropriate for investigating the direct and indirect causes of fertility differentials. It is shown that direct and indirect effects on fertility do not always operate uniformly between the two rural sub-sectors. On the basis of the findings, conclusions and recommendations are drawn.
\end{abstract}

\section{Introduction}

Zimbabwe covers an area of $390757 \mathrm{~km}^{2}$ and is divided into eight administrative Provinces. The Provinces are further subdivided into 53 districts. Outside the commercial farming areas and State lands, there are two types of rural settlements, namely communal areas and resettlement schemes. Over 75 percent of the population lives in the communal areas, which were set aside by the former colonial administration exclusively for the African population. Up to independence, in 1980, these areas were overpopulated and underdeveloped. Since independence, the Government has initiated various programmes to try to solve the problem of communal area underdevelopment. Such efforts include resettling some of the overcrowded rural population in the purchased, formerly white-owned large scale commercial farms; and the establishment of growth centres in communal lands in order to bring about employment opportunities and modernisation infrastructure closer to the majority of the population.

\footnotetext{
${ }^{1}$ An abridged version of a study funded by the Rockefeller Foundation, Mac Arthur Foundation, the Swedish International Development Cooperation Agency (SIDA/SAREC), through the Union for African Population Studies in 1997
} 
There were three of the aims of the original resettlement programme that are of direct socio-economic relevance to this survey, namely to:

1) Improve the standard of living of the largest and poorest of the population of Zimbabthe; ;/aps.journals.ac.za

2) Expand or improve the infrastructure and services that are needed to promote the well-being of the people and economic production;

3) Provide, at the lower end of the socio-economic scale, opportunities for people who have no land and who are without employment and may, therefore, be classed as destitute (GOZ, 1992).

There were four basic planning models in the original resettlement programme. However, only the Normal Intensive Model A is of direct relevance to this paper. The model was based on detailed and careful planning, provision of large amounts of specialist inputs, including the provision of a wide range of infrastructure and agricultural extension services to serve the newly resettled communities. Each scheme was to consist of a nucleated village settlement with individual arable family land allocations of 5 hectares, provisions for 5-15 livestock units, and grazing rights on communal pasture .Each male settler, supposedly, the household head, was to be allocated a residential plot. The Report of the Monitoring and Evaluation Unit of the Ministry of Lands, Agriculture and Rural Resettlement described Model A Schemes as follows:

On a comparative basis, the provision of infrastructure on Resettlement Schemes has been greater than that existing in the Communal Areas. The increased access to infrastructure of schools, clinics and water facilities leads the report to conclude that the standard of living of the programme-beneficiaries has improved (GOZ 1992, iii).

Other studies appear to confirm that, compared to the communal areas, resettlement schemes have better access to land and agricultural inputs (Gwebu 1990, 1991). However, most are seriously undersupplied in terms of infrastructure such as transport and communication networks, schools, clinics, water supply, and shopping facilities, especially in the Accelerated Model A Schemes.

Detailed socio-economic surveys have shown that, in spite of the geographical contiguity of the communal lands and resettlement schemes, structurally and functionally, they portray wide differences in terms of institutional configuration, infrastructure availability, access to services, economic development profiles, and population composition (Gwebu 1990, 1991). 
Two of the most important variables that account for fertility differentials are education and occupation (Martin 1995, Caldwell 1980, Easterlin 1980, Blake 1974, Hawthorn 1970). In the study area, it was found that $59.3 \%$ of resettlement area population had been to primary school compared with $52 \%$ of the communal area residents. Hownever, $15.3 \%$ of the communal area population had attained post primary education compared to $10.4 \%$ among the resettlement area dwellers. $26.2 \%$ of the economically active population in the resettlement schemes was employed as farmers whereas $22 \%$ in the communal area were so employed. The rest of the residents of the communal lands had relatively greater access to job opportunities outside the agricultural sector. These observed socio-economic differences are bound to cause a sharp distinction between resettlement areas and the communal lands in terms of their demographic and other major socio-economic characteristics, which have crucial implications for fertility (Gwebu 2000)

This paper seeks to fulfil two main objectives, namely, to: compare the fertility levels between communal and resettlement areas; and to account for the differences in these levels, in terms of both direct and indirect effects.

\section{The Research Problem}

Studies on fertility in Zimbabwe have either described national trends, identified differences between urban and rural sectors, or highlighted differences among women belonging to distinct socioeconomic backgrounds. In this context, it has been observed, for example, that Zimbabwe's crude birth rate declined from $44 / 1000$ in 1982 to $34.5 / 1000$ in 1992 (CSO, 1995). Total fertility rate (TFR) fell from 5.5 in 1988 to 4.3 in 1994. Urban areas posted a TFR of 3.1 compared with a rural TFR of 4.9. Women with secondary education and above had a TFR of 3.3 compared with 4.7 and 5.2 for women with primary and no education at all, respectively (COS, 1995).

Studies on the determinants of fertility in Zimbabwe have noted that the transition appears to have begun in the mid-1980s; they have further observed that some of the key factors that may be responsible for this achievement are high levels of education, relatively low levels of infant and child mortality, and a well-designed family planning program (Guilkey and Jayne, 1997:173). Later entry into marital unions, associated with female education, has been cited as a main contributory factor to the national decline in fertility (CSO, 1995). By 1994, entry into marriage had increased from 18.9 years among women aged 40-49, to 19.8 years among those aged 20-24, and age at first birth increased from 19.3 to 19.7 years among women aged 30-34 and 25-29 years, respectively. 
Another important determinant of fertility decline was knowledge and use of modern contraceptives associated with a good family planning programme (Boohene et al., 1991; Edwards, 1996; Adamchak and Mbizvo, 1990). Knowledge of at least one modern contraceptive method increased from 83 percent in 1984, to htgp://aps.journals.ac.3a8 percent in 1988 , and 98 percent in 1994, among women within the reproductive age group (CSO, 1995).

Whilst the above analyses are useful for international comparisons of fertility differential patterns and transition trends, they conceal important differences, which may exist at the micro-scale, such as within the urban or rural areas. Most importantly, previous studies have depicted mainly the direct effects of socio-economic and background variables of fertility. They have therefore failed to address the important indirect effects background factors that operate through proximate variables.

Previous demographic and socio-economic studies, such as those conducted by the Demographic and Health Survey and the Central Statistical Office in Zimbabwe, have furthermore treated communal and resettlement rural subareas as one uniform geographical entity. However, a number studies on levels of fertility differentials have clearly shown that variations tend to exist between areas at different phases of socio-economic development (Bulatao and Casterline 2001; Bailey and Weller, 1987). Demographic and Health Surveys (DHS) and Contraceptive Prevalence Surveys (CPS) have adopted sample survey methodologies, for studying population characteristics in Zimbabwe. They present their data findings in an aggregated format. Whilst these research designs may be useful for comparative purposes globally, they nonetheless have inherent problems.

For example, the acclaimed status of Botswana and Zimbabwe as being at the forefront of the demographic transition, in sub-Saharan Africa, has generated substantial and controversial debate (Thomas and Muvandi, 1994; Blanc and Rutstein, 1994). For instance, it has been argued that the alleged decline in both countries can be attributed to differences in sample compositions from either census, CPS or DHS surveys. It has also been claimed that differences in the design of fertility questionnaires between the CPS and DHS schedules could have contaminated inferences drawn from the descriptive aggregate statistics (Thomas and Muvandi, 1994).The other main drawback of DHS and CPS studies is that they do not shed light on any interactive effects which characterize the direct and indirect variables that determine fertility. 
A number of studies have however attempted to address these problematic issues (Kar, 1978; Guilkey and Jayne, 1997; Agha and van Rossem, 2002). Guilkey and Jain's approach is of particular relevance for this study. Using data from the 1989 Zimbabwe Demographic and Health Survey (ZDHS), combined with a Service Availability Survey condurcted in 1990 , they addressed the effect of intentions to restrict fertility and access to services in determining contraceptive use, through a structural equations model that included both fertility intentions and current contraceptive method choice as outcomes. The major methodological limitation of the above study was, however, that like its predecessors, it did not differentiate between the rural and urban areas, nor did it focus on the rural sub-area differentials.

Communal and resettlement localities differ markedly in their levels of socio-economic and commercial development. Communal areas have, for instance, relatively better established educational facilities, health care delivery services, transport and communication infrastructure. The communal lands are moreover functionally and structurally better integrated into the mainstream of the urban-industrial core regions of the national space economy. Contradistinctively, the resettlement areas are simply contiguous resource frontier regions characterised by the teething problems of incipient settlement, such as lack of sufficient physical and socio-economic facilities, coupled with poor connectivity with the national space economy (Gwebu, 1990; 1991).

On the basis of the sub-cultural hypothesis, communal and resettlement areas do constitute two clearly distinct socio-economic subcultures with wellcontrasted norm and value systems. To the extent that it is accepted that socioeconomic development is a key control variable of the dynamics of demographic processes (UNECA, 1990; 1991, Easterlin, 1980), it is expected that fertility level differentials should reflect the sub-regional development dissimilarities.

Is this indeed the case with communal and resettlement areas in rural South-western Zimbabwe?

\section{Theoretical Basis of Fertility Differentials over Geographical Space}

Spatially, fertility differentials exist at various geographical scales because different sub-regions have attained different stages of the fertility transition. Globally, developed countries record lower fertility levels than developing countries (Population Reference Bureau, 2002). Nationally, urban and rural areas resonate the above parallel trend. Intra-rural studies have also shown variations in fertility levels, based on their different levels of socio-economic development (Jain 1985, Coward, 1986). 
The lead and lag sub-regions reflect differences between such areas in terms of their socio-economic and structural characteristics, and the adoption of reproductive behavioural regulation, associated with innovation diffusion (Rogers, 1995). Certain factors act as catalytic agents in the process of diffusion and adoption of fertility regulation innovations. These include the personal attributes of the potential adopters, the availability of supportive infrastructure, socio-economic facilities and socio-cultural systems. Personal attributes encompass such factors as level of education, types of occupation, sociocultural value systems (Kokole, 1994; Poo Tan and Tey, 1994) and the stage in the life cycle of the potential adopter. Infrastructure includes transport and communication networks. Socio-economic services are health and educational institutions, and the mass media. Socio-economic opportunities include levels of participation by potential adopters in the economic, educational and sociopolitical activities. Socio-cultural value systems and norms include aspects such as secularization. These are influenced by each individual's stage in the life cycle, which is closely associated with age.

A number of sub-national studies have established the existence of differentials either between urban and rural areas or among rural districts. The rational choice of how many children to have is determined by both the personal and locational characteristics of the individual on geographic space (Gwebu, 2000). For example, in his study of urban-rural spatial differentials on fertility, in Barbados, Jones interpreted the pattern through "the ecological theory of metropolitan dominance" by which cities exert an organizing influence on the social structure of their hinterlands by the diffusion of urban norms and values, so that gradient patterns in socio-economic characteristics are established (Jones, 1990). Jain's study of inter-district variations of fertility, in rural India, clearly brought out the influence of modernization and development infrastructure (Jain, 1985).

The working hypothesis of this study is therefore that fertility differentials between communal areas and resettlement schemes reflect their differences in socioeconomic development.

\section{Methodology}

This study attempts to analyze fertility determinants, for the married mothers aged 15-49 within a set of selected communal and resettlement areas of Zimbabwe, by separating their complex causal relationships, on the basis of their direct and indirect effects. The path analysis model is considered as most appropriate for handling this research problem (Blalock, 1969; Blalock, 1971; Asher, 1983; Berry, 1984). Two sets of data were required for the research, i.e. secondary and primary data. 


\section{Secondary Data Sources}

Background information about the study area was obtained, in the form of:

$$
\text { http://aps.journals.ac.za }
$$

i) Topographical and locational maps, sourced from the Surveyor General and the Department of Rural Development, respectively;

ii) Government Ministry Reports, such as census documents, Provincial Development Plans, District Reports on health, education, transport and communication, agricultural and technical extension services, Provincial and District family planning documents;

iii) Other supportive archival literature such as books and journals, obtained from the Bulawayo municipality, University and College libraries.

\section{Primary Data Sources and Sampling Procedures}

The population consisted of all married mothers within the reproductive age group. Primary data were collected from the respondents through two sets of interview instruments. The instruments were modified questionnaire sets derived from an earlier socio-economic survey of the area by the author (Gwebu, 1991), the Central Statistical Office and the Demographic and Health Survey questionnaires. The first set sought quantitative survey data. The second set sought qualitative information through focus group discussions.

The Dombodema resettlement scheme, a Normal Intensive scheme, and the adjacent communal areas in southwest Matabeleland were the spatial focus of the study. The author was already familiar with the areas from previous rural socioeconomic surveys. The villages in the resettlement areas are designated by number. The list of resettlement villages constituted the sampling frame of the villages for the study.

A multiphased sampling procedure was then adopted. A 30\% sampling fraction was used. Initially, a random sample of villages was selected from the resettlement

villages. Each village area consists of about 20 households. Within each of these, a subset of households was then randomly chosen in order to ensure representativeness. Communal land census enumeration areas which share a boundary with the resettlement scheme were identified. Villages within the communal lands are designated by name. These were listed to constitute the communal area sampling frame. $30 \%$ of the households were selected randomly from the set. An entire coverage of the selected households from the respective sub-sectors was made in order to obtain the required general demographic and socio- economic data. 
In this way, data on 832 married women from the resettlement area and 710 from the communal land villages were obtained. Quantitative information on fertility patterns and their correlates was extracted for all the married mothers within the ages of 15-49, among the targeted households. In order to complement and provide substance to the quantitative survey findings, qualitative information was obtained through in-depth-interviews and focus group discussions.

From the earlier socio-economic field surveys, it had been learned that mixed groups tend to be inhibited in their responses to certain questions. Moreover, mixed groupings tend to provide distorted and exaggerated responses. Finally, it is culturally anathema to conduct discussions on certain socio-culturally-sensitive issues on sexuality and reproductive health, within the confines of mixed groups. It was for these reasons that the interview groups were stratified, by gender. Focus group discussions were conducted separately with mothers and fathers.

Focus group discussions with the fathers were conducted under the local Councillor and Village Development Committee (VIDCO) chairmanship. The researcher acted as secretary for the deliberations. At each Village, the fathers were subdivided into small subgroups of, at most, 5 persons. Focus group discussions with the mothers were conducted under the chairmanship of the Community Based Distributor. Selected Village Community Workers acted as secretaries. At each Village, mothers were subdivided into small groups of 5 persons.

\section{The Variables Used in Path Analysis}

Table 1 depicts the numeric codes, labels, brief description and scale of measurement of each variable used in the study. The dependent variable is the number of children ever born to married women aged 15-19. The background variables are woman's age, her language and religious affiliation. The socioeconomic variables are the woman's occupation and level of education. The demographic determinants are age-at-first -marriage, duration of union, desired family size, preference of sex of child, average length of lactation, duration of contraception and length of abstinence. 
Table 1: Variables Used in the Analysis

\begin{tabular}{|c|c|c|c|c|}
\hline Variable & $\begin{array}{l}\text { Numeri } \\
\text { Code }\end{array}$ & Label & Value & Scale \\
\hline Age & 1 & \multicolumn{2}{|c|}{ http://apsfidEurnals ac Years } & Interval \\
\hline Religion & 2 & REL & 1-Pentecostal 0-Other & Dichotomous \\
\hline Ethnicity & 3 & LANG & 1-Kalanga 0-Other & Dichotomous \\
\hline Education & 4 & EDUCTN & Years & Interval \\
\hline Occupation & 5 & ECON & 1-Hsewife/farmer 0-other & Dichotomous \\
\hline Age at Marriage & 6 & AFRST & Years & Interval \\
\hline Child Sex Preference & 7 & CHMLE & Total males & Interval \\
\hline Lactation (post partum) & 8 & BFDG & Months & Interval \\
\hline Desired Family Size & 9 & DFLSZ & Size & Interval \\
\hline Abstinence(post partum) & 10 & ABSTNC & Months & Interval \\
\hline Contraception & 11 & CONTR & Years & Interval \\
\hline Duration of Union & 12 & UNION & Years & Interval \\
\hline Children Ever Born & 13 & CEB & Number Live Births & Interval \\
\hline
\end{tabular}

\section{Model Definition}

A detailed analysis of the role of these descriptive factors has been conducted elsewhere (Gwebu 2001). For the present study, it is pertinent to note that the overall Fertility Grand Mean of Children Ever Born for the resettlement schemes was higher than that of the communal lands. This could have been due to three main reasons. Firstly, this could be reflective of the differential impacts of modernization institutions and family planning agencies between the two sub-sectors. Secondly, the differences might be indicative of the relative importance attached to child labour in relation to the major economic activities pursued within the respective sub-sectors. For instance, whereas agriculture constitutes the economic mainstay of the resettlement sub-area, its future viability in the communal lands now remains uncertain for most families because of the low carrying capacity of the land, associated with overpopulation. Finally, mothers in the resettlement areas tend to be younger. Whilst the above results are useful for descriptive purposes, they do not highlight the functional direct and indirect factors which impact on fertility. Path analysis is, therefore, used for the analysis because it overcomes these limitations (Blalock, 1969; 1971; Asher, 1983; Berry, 1984). It also facilitates the measurement of the combined effect of both direct and indirect determinants of fertility.

Figure 1 depicts the hypothesized ordering of these variables in diagrammatic form (Asher, 1983; Berry, 1984). The number of children ever born (CEB) is taken to depend either directly or indirectly on the twelve variables, specified in the above Table. Seven of the determinants appear to be affecting fertility directly and the rest indirectly, according to the above model specification. 


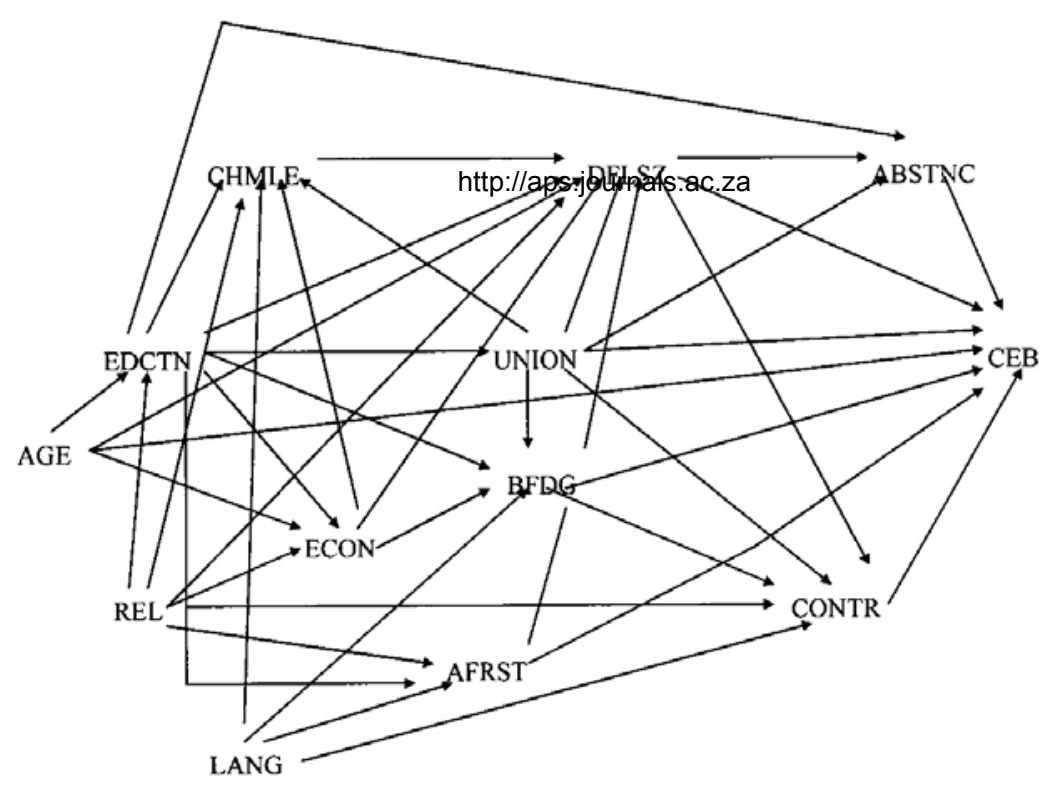

Figure 1: Direct and indirect factors on Mean Number of Children Ever Born

In words and briefly, age, religion and ethnicity are regarded as exogenous variables in the model. The level of education should be influenced by age as well as religious affiliation. In the study area, certain religious sects attach minimal value to formal education.

Economic activity should depend on the level of education, the woman's age, as well as her religion. Her age-at-first-marriage should be controlled by the number of years spent at school, religious and ethnic affiliation. Child sex preference should depend on religious and ethnic affiliation of the mother, her level of education and her type of economic activity.

Duration of post-partum lactation should be controlled by level of education and should be least among the educated. Certain types of economic activity, especially those pursued away from the domestic environment are incompatible with breast-feeding. Ethnic beliefs also usually regulate the duration of breast-feeding. Desired family size should depend on the gender composition of the siblings. Where there are only or mainly female children, the tendency in traditional African societies is to continue child-bearing for the sake of reproducing male children in order to perpetuate the clan name and to ensure old age security. Education as well as age should have a depressive effect on desired family size. Traditional and certain Pentecostal religious sects tend to be pro-natalist, for socio-cultural and fundamentalist reasons, respectively.

Generally, labour-intensive economic activities generate a desire for more children to assist parents with their agricultural and domestic tasks. Where 
marital unions are relatively recent, it is expected that, holding other factors constant, the desired number of children should be relatively high. Abstinence, as a method of birth control, should be higher among the less educated women for economic and traditional reasons. In the absence of modern contraception, it is an important mechanism for regulating fertility. Elderly couples should find it relatively easier, than younger ones, to abstain longer.

Utilisation of modern contraception should be determined by desired family size, duration of lactation, religious and ethnic belief systems. Contraception is expected to be relatively more stringently enforced among recently constituted unions. Duration of union should depend on level of education, religious affiliation (certain sects enter very early), and age.

There are seven direct effects on fertility as suggested by the last structural equation, under Notes, at the end of this paper. It is expected that age and ageat-first-marriage are negatively related to fertility. Duration of lactation lengthens post-partum amenorrhoea and should have a depressive effect on fertility. The desired family size is normally a reliable and direct predictor of fertility performance. Duration of abstinence should be negatively related to fertility as should be that of contraception use. Fertility is expected to occur mainly within marital unions, and the longer the union then the higher the expected fertility.

\section{Model Operationalization}

There are three broad procedures for operationalizing the model. First, direct and statistically significant determinants of fertility are selected, using the normal multiple regression format:

$y=b_{o}+b_{1} x_{1}+b_{2} x_{2}+\ldots b_{k} x_{k}+\varepsilon$

Where $\mathrm{y}$ is the number of children ever born; $\mathrm{b}_{\mathrm{o}}$ is the intercept; $x_{i}$ is the partial regression coefficient; $b_{i}$ is the slope and $\varepsilon$ is an error term assumed to follow a normal distribution with zero mean and constant variance. Secondly, a sequence of ordinary least squares regressions are performed on each significant direct determinant, for path analysis. Finally, the combined effect of the independent factors is established. A detailed of these procedures can be found under the Notes, at the end of this paper. 
Desired family size promotes rural fertility as a result of rural household economic considerations. Investment motives thus feature prominently in the calculus of ultimate reproductive behavior. Children are regarded as an asset in that they provide emotional, financial and material security both to the immediate and extended family. perceived probability of realizing prosperity for the family.

To the farmer housewife in the resettlement area, the size of the family-is critical for domestic chores, agricultural production, and social security:

Eight is a good number. Those can help us in our domestic activities, farming, an when we get old they will look after us.

Desired family size also prompts high fertility where infant and child mortality are relatively high. This is generally the case in the rural areas. Under such conditions, high fertility becomes a rational choice strategy because replacement births ensure that some of the children will at least survive infant and childhood mortality.

The elderly women naturally record a higher cumulative fertility in both sub-sectors.

The duration of lactation variable adds significantly to fertility regulation in the communal lands unlike in the resettlement areas, where it comes up as being insignificant. Apparently, those women who lactate longest after giving birth have higher cumulative fertility. These are the elderly women. Modern contraception is relatively more important in regulating fertility in the resettlement sub-sector. Again, it is those who have been contracepting longest who record higher cumulative fertility. The impression given by the results is that regardless of sector, it is the elderly women who are committed to fertility regulation either by naturally prolonging post-partum amenorrhea or using modern methods of contraception. In that sense, contraception seems to be used for birth-spacing rather than for limiting family size.

There exist strong socio-cultural, moral, health, religious prejudices that are associated with the relatively low prevalence of contraception, among the young couples in the study area. Most young of the husbands are target migrants to Botswana and South Africa. They question the intrinsic relevance and necessity of contraception, categorically, on the basis of their long absence from their home areas. Culturally, contraception is associated with moral turpitude on the part of the contraceptor. A representative of the fathers in the communal lands had this to say on this issue: 
"Why should everybody use birth control, including our own children? Soon everybody will be having sex all over here just like that."

Contraception is also regarded as operating against the fundamental dictates and natural logic of procreation. hittp://aps.journals.ac.za

"Why?" the resettlement area men retorted, "... should these young women convert their wombs into graveyards for the unborn"?

Even among the women who use modern methods of contraception, most remain apprehensive about the practice.The bulk of those who have adopted this innovation rely on reversible contraceptives, such as the pill and injectables. The main reasons given for preferring reversible contraceptives includes their reliability and safety.

Not all reversible contraceptives are popular though. Reasons for either apprehension rejection of certain oral and injectable contraceptives stem from their suspected clinical side-effects such as headaches, backaches, nausea, spotting, breakthrough bleeding, heavy bleeding and amenorrhoea. Other commonly feared side-effects include loss of libido, acne, dry vagina, leg and abdominal cramps and, in some cases, galactorrhoea and thromboli-emboli. The fear of giving birth to congenitally deformed infants was also expressed.The condom is rapidly gaining popularity for two main reasons. Besides being a contraceptive, the condom is perceived to facilitate STD-free sex.

\section{Estimation Procedures for Indirect Effects on Fertility}

Path analysis is the operational basis of the model. Path analysis consists of a sequence of linear regressions (Blalock 1969, Blalock 1971, Asher 1983, Berry 1984). The option used here consists of recursive, cycle-free asymmetric networks. The path coefficients are standardized ordinary least squares regression coefficients. Each path coefficient $p_{\mathrm{ij}}$ denotes the relative strength of the contribution of independent variable ${ }_{j}$ in explaining dependent variable. The schematic causal network model used here makes four basic assumptions stated in Note 1, at the end of the paper. 
The preceding discussion has focused on direct determinants of mean number of children ever born. Some of these direct factors also affect fertility indirectly. Moreover, they themselves may be intermediate to other indirect factors. The statistically significant paths to lifetime fertility, at $\alpha=0.05$ level, are illustrated in Figure 2, for the two rural sub-sectors.

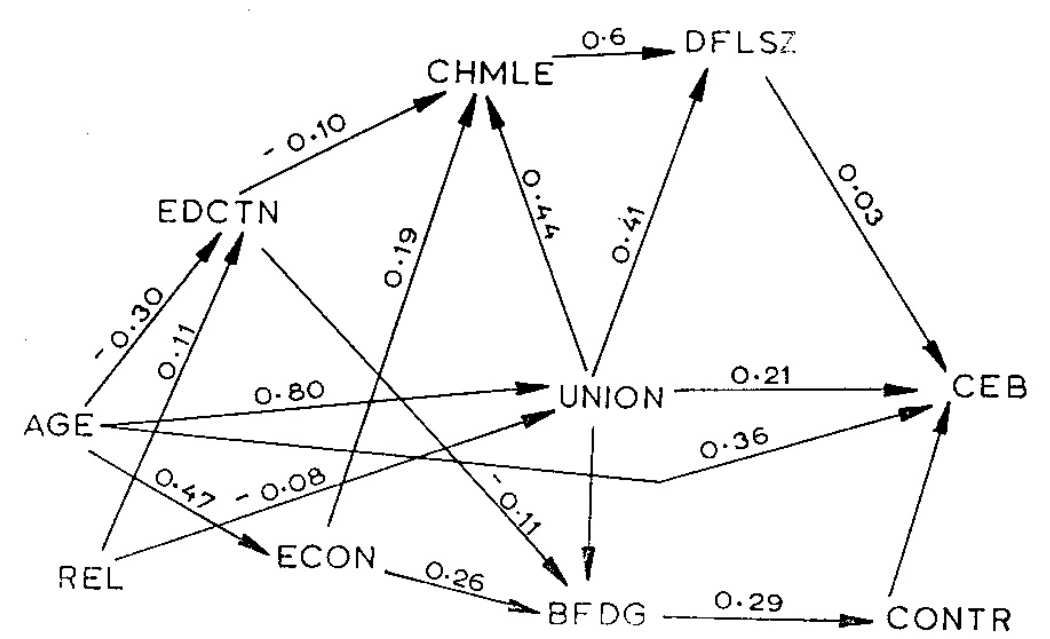

Figure 2a: Significant Paths to Resettlement Area Lifetime Fertility

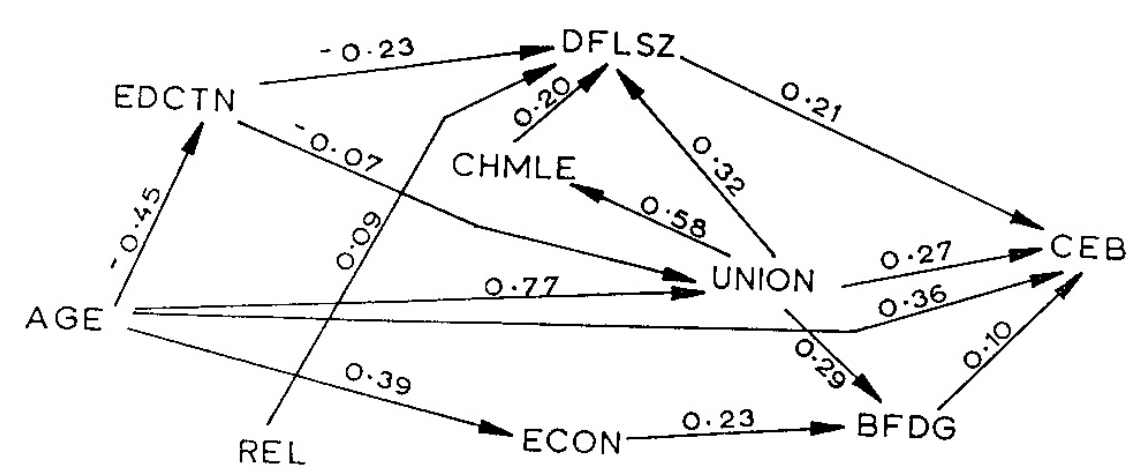

Figure 2b: Significant Paths to Communal Area Lifetime Fertility 
The web of paths presents a wide diversity of instructive scenarios. However, the following section will deal mostly with the indirect effects of the four significant direct determinants of fertility identified earlier on in order to keep the discussion focused.

$$
\text { http://aps.journals.ac.za }
$$

Duration of union affects fertility both directly and indirectly, in the two rural sub-areas. For the resettlement areas, the indirect effects take the form:

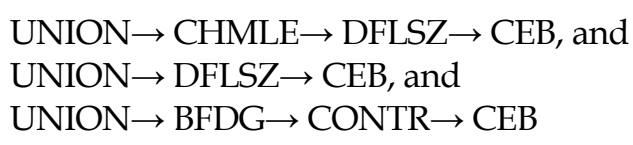

The summation for these indirect effects takes the form specified in Note 3 :

The sum effect is equivalent to 0.026 .

For the communal areas, the indirect effects take the form:

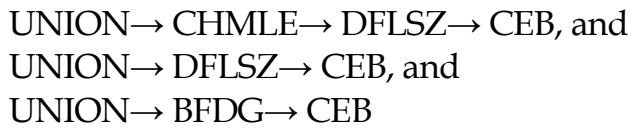

The summation for these indirect effects is of the form specified under Note 4 . The sum effect is equivalent to 0.122 .

The total indirect effects of the duration of union variable are stronger for the communal lands. The strongest contributing path involves the positive relationship between duration of union and the total number of male children. This came as unexpected for an African setting. In-depth interviews and focus group discussions, however, revealed that adult female children are credited with showing greater family responsibility and are more accountable when compared with their male counterparts:

In our culture, it is not good to have children of only one sex. Girls and boys are both helpful, but girls grow up to be more dependable and reliable.

The strongest contributing path in the resettlement areas is that linking desired family size and the total number of male children. This was rationalized as follows:

A suitable sex composition in any family should be made up of boys and girls. Preferably, there should be more girls. Girls never forget their parents, whether they get married or if they get employment in South Africa. 
The age variable also affects the mean number of children ever born both directly and indirectly. The sum of the indirect effect of age for the resettlement sub-sector is specified in Note 5.This translates to 0.028 .

For the communal areas, the stt://aps.journals.ac.za effects for the age variable is outlined in Note 6 . This becomes 0.341 . The indirect effects of the age variable on lifetime fertility are therefore more pronounced for the communal lands than the resettlement areas. In both rural sub-sectors, however, the strongest path relates woman's age directly with the duration of union. This is as should be the case since cumulative fertility naturally increases with age and family formation takes place within established unions.

Like education, religion is exogenous to lifetime fertility, as depicted in Figure 2. The sum of the indirect effects for the resettlement areas is -0.019 . This implies that Pentecostals have lower CEB. This is most likely because they are relatively younger. That for the communal lands is 0.019 .The implication here is that women of other religious faiths record lower fertility. This could be a result of their comparative receptiveness to fertility regulation methods.

\section{Summary, Conclusions and Recommendations}

In general, studies on spatial fertility differentials have treated the rural sector as a single and uniform geographical entity. This empirical study, based on quantitative analysis and participatory methodologies, has stratified the rural sub-sector in south-western Zimbabwe, into communal lands and resettlement schemes, in order to investigate fertility differentials.

The results from the bivariate description of the differentials show that resettlement areas do have higher fertility as compared with the communal lands and several reasons have been put forward to account for this. Any policy and programmes aimed at fertility regulation needs to realize the existence of these differences.

Results from a general multiple regression model on the direct effects of fertility show that the duration of union and desired family size promote fertility in both rural sub-sectors. The elderly women tend to record higher fertility in both sub-sectors, naturally.

The lactation duration variable adds significantly to fertility regulation in the communal lands unlike in the resettlement areas, where it comes up as being insignificant. Apparently, those women who lactate longest also post higher cumulative fertility. These are the elderly women. Modern contraception is relatively more important in regulating fertility in the resettlement sub-sector. It is those women who have been contracepting 
longest who record higher cumulative fertility. The impression given by the results is that regardless of sector, it is the elderly women who are committed to fertility regulation either by naturally prolonging post-partum amenorrhea or using modern methods of contraception. In that sense, contraception is used more for birth spacing rather than for limiting family size. Any meaningful family planning programmers needs to be sensitive to both the immediate and ultimate aims of fertility control measures adopted by women in the different age groups and sub-sectors.

Socio-cultural and perceptual factors on modern contraception types and their possible effects have a large bearing on the reproductive concerns and practices among the younger women. The use of the male condom is becoming increasingly important because of its dual role as a contraceptive and because it is perceived as a protective measure against the transmission of STDs, particularly HIV/AIDS. The imagined and real side effects of modern contraceptive innovations need to be thoroughly investigated. Most family planning programmes tend to focus mostly on the supply side rather than the demand side of innovation diffusion.

Results from path analysis show the direct, indirect and combined effects of fertility determinants in the two sub-sectors. The total indirect effect of the duration of union variable is stronger for the communal lands. The strongest contributing path in the resettlement areas links desired family size with the total number of male children. Ultimately these results are consistent and reconcilable in the sense that they underlie the value and trust attached to the female migrants.

Both age and religion differentiate communal and resettlement area fertility levels. This indicates the necessity of focusing fertility regulation on the basis of these factors.

\section{Notes}

1.

a) The specification of the causal ordering between and among the variables, including those which are causally prior and exogenous to all the others (Blalock 1969, Blalock 1971,Asher 1983,Berry 1984).

Figure 1 depicts the ordering of these variables in diagrammatic form. The illustration is assumed to be isomorphic with the algebraic and statistical properties of the postulated variable interactions in the system.

b) 1 is assigned to a numerically dominant subgroup, in the case of dichotomous variables.

c) Relationships between the variables are linear and additive, i.e. each total path regression is the sum of its constituent elementary paths.

d) The error terms $\varepsilon_{i}$ are assumed to be uncorrelated with all prior variables and hence with each other. 
$\mathrm{EDCTN}=\mathrm{b}_{4.0}+\mathrm{b}_{4.1} \mathrm{AGE}+\mathrm{b}_{4.2} \mathrm{REL}+\varepsilon_{1}$

$\mathrm{ECON}=b_{5.0}+b_{5.1} \mathrm{AGE}+b_{5.2} \mathrm{REL}+\mathrm{b}_{5.4} \mathrm{EDCTN}+\varepsilon_{2}$ http://aps.journals.ac.za

AFRST $=b_{6.0}+b_{6.2} R E L+b_{6.3}$ LANG $+b_{6.4}$ EDCTN $+\varepsilon_{3}$

CHMLE $=\mathrm{b}_{7.0}+\mathrm{b}_{7.2} \mathrm{REL}+\mathrm{b}_{7.3} \mathrm{LANG}+\mathrm{b}_{7.4} \mathrm{EDCTN}+$

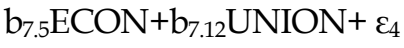

BFDG $=b_{8.0}+b_{8.3}$ LANG $+b_{8.4}$ EDCTN $+b_{8.5} E C O N+b_{8.12} \mathrm{UNION}+\varepsilon_{5}$

DFLSZ $=b_{9.0}+b_{9.1} A G E+b_{9.2}$ REL $+b_{9.4}$ EDCTN $+b_{9.5}$ ECON $+b_{9.6}$ AFRST $+b_{9.7} \mathrm{CHMLE}+\mathrm{b}_{9.12} \mathrm{UNION}+\varepsilon_{6}$

$\mathrm{ABSTNC}=\mathrm{b}_{10.0}+\mathrm{b}_{10.4} \mathrm{EDCTN}+\mathrm{b}_{10.9} \mathrm{DFLSZ}+\mathrm{b}_{10.12} \mathrm{UNION}+\varepsilon_{7}$

CONTR $=b_{11.0}+b_{11.2}$ REL $+\quad b_{11.3}$ LANG + $b_{11.8} B F D G+b_{11.9} D F L S Z+b_{11.12} U N I O N+\varepsilon_{8}$

$\mathrm{UNION}=b_{12.0}+b_{12.1} \mathrm{AGE}+b_{12.2}$ REL $+b_{12.4} \mathrm{EDCTN}+\varepsilon_{9}$

$\mathrm{CEB}=b_{13.0}+b_{13.1} \mathrm{AGE}+\mathrm{b}_{13.6} \mathrm{AFRST}+\mathrm{b}_{13.8} \mathrm{BFDG}+\mathrm{b}_{13.9} \mathrm{DFLSZ}$

$+b_{13.10} \mathrm{ABSTNC}+b_{13.11} \mathrm{CONTR}+\mathrm{b}_{13.12} \mathrm{UNION}+\varepsilon_{10}$

3. $\quad \mathrm{P}_{12.7} \mathrm{P}_{9.7} \mathrm{P}_{13.9}+\mathrm{P}_{12.9} \mathrm{P}_{13.9}+\mathrm{P}_{12.8} \mathrm{P}_{11.8} \mathrm{P}_{13.11}$

4. $\quad \mathrm{P}_{12.7} \mathrm{P}_{9.7} \mathrm{P}_{13.9}+\mathrm{P}_{12.9} \mathrm{P}_{13.9}+\mathrm{P}_{12.8} \mathrm{P}_{13.8}$

5. $\quad \mathrm{P}_{4.1} \mathrm{P}_{7.4} \mathrm{P}_{9.7} \mathrm{P}_{13.9}+\mathrm{P}_{4.1} \mathrm{P}_{8.4} \mathrm{P}_{11.8} \mathrm{P}_{13.11}+\mathrm{P}_{12.1} \mathrm{P}_{12.7} \mathrm{P}_{9.7} \mathrm{P}_{13.9}$

$+\mathrm{P}_{12.1} \mathrm{P}_{12.9} \mathrm{P}_{13.9}+\mathrm{P}_{5.1} \mathrm{P}_{8.5} \mathrm{P}_{11.8} \mathrm{P}_{13.11}+\mathrm{P}_{12.1} \mathrm{P}_{12.8} \mathrm{P}_{11.8} \mathrm{P}_{13.11}$

6. $\mathrm{P}_{4.1} \mathrm{P}_{9.4} \mathrm{P}_{13.9}+\mathrm{P}_{12.2} \mathrm{P}_{12.7} \mathrm{P}_{9.7} \mathrm{P}_{13.9}+\mathrm{P}_{12.1} \mathrm{P}_{12.7} \mathrm{P}_{9.7} \mathrm{P}_{13.9}+\mathrm{P}_{12.1} \mathrm{P}_{12.9} \mathrm{P}_{13.9}$ $+\mathrm{P}_{12.1} \mathrm{P}_{13.12}+\mathrm{P}_{12.1} \mathrm{P}_{13.12}+\mathrm{P}_{12.1} \mathrm{P}_{12.8} \mathrm{P}_{13.8}+\mathrm{P}_{5.1} \mathrm{P}_{8.5} \mathrm{P}_{13.8}+\mathrm{P}_{4.1} \mathrm{P}_{12.4} \mathrm{P}_{12.8} \mathrm{P}$ 138

$+\mathrm{P}_{5.1} \mathrm{P}_{8.5} \mathrm{P}_{13.8}+\mathrm{P}_{4.1} \mathrm{P}_{12.4} \mathrm{P}_{12.8} \mathrm{P}_{13.8}+\mathrm{P}_{4.1} \mathrm{P}_{12.4} \mathrm{P}_{13.12}$ 


\section{References}

Adamchak, D.J.; Mbizvo, M.T. 1990. The Relationship between Fertility and Contraceptive Prevalence In Zimbabwe. International Family Planning Perspectives, 16:103-111

Agha,S.,van Rossem,R. 2002. Impact of Mass Media Campaign on Intentions to Use the Female Condom in Tanzania. International Family Planning Perspectives.28:151-158.

Asher,H.B. 1983. Causal Modelling.Beverly Hills, CA, Sage.

Bailey,M. and Weller R.H. 1997. Fertlity Differentials in Sierra Leone. Journal of Developing Areas 21 191-208.

Berry,W.D. 1984. Nonrecursive Causal Models. Beverly Hills,CA,Sage.

Blanc,A.K.,Rutstein S.O. 1994. Fertility Trends in Southern Africa: A Debate on the Demographic Transition in Southern Africa: Yet another Look at the Evidence from Botswana and Zimbabwe. Demography, 32:209-215.

Blake,J. 1974. The Changing Status of Women in Developing Countries. Scientific American.233:91-101.

Blalock,H.M. 1969. Theory Construction: from Verbal to Mathematical Formulations. Englewood Cliffs, Prentice Hall.

Blalock,H.M. 1971. Causal Models in the Social Sciences. Chicago. Aldine.

Boohene, E.; Tsodzai,J.;Hardee-Cleaveland,K.; Weir,S.;Janowitz,B. 1991. Fertility and Contraceptive Use among Young Adults in Harare, Zimbabwe. Studies in Family Planning, 22,264-271.

Bulatao,R.A;Casterline J.B. 2001. Global Fertility Transition. New York. Population and Development Review.Population Council.

Caldwell, J.C. 1980. Mass Education as a Determinant of the Timing of Fertility Decline. Population and Development Review, 6, 225-256.

Central Statistics Office. 1995. Zimbabwe Demographic and Health Survey 1994. CSO\& Institute for Resource Development/Macro Systems Inc. Harare.

Coward, J. 1986. The Analysis of Regional Fertility Patterns. In Woods and Rees (eds.) Population Structures and Models. Allen and Unwin, London.

Demographic and Health Surveys. 1991. Zimbabwe Service Availability Survey 1989/90. CSO. Harare.

DHS. 1991. DHS Findings Presented at World Conference in Washington.

DHS Newsletter. 4.

Easterlin, R.A. 1980. Fertility and Development. Population Bulletin of ECWA. 18: 5-40.

Edwards,S. 1996. Fertility Has Fallen in Zimbabwe, Reflecting Rising Contraceptive Use and Desires for Smaller Families. International Family Planning Perspectives.22:46-49.

Government of Zimbabwe. 1992. Resettlement Programme: Policies and Procedures. MLRRD. Harare.

Guilkey, D., Jayne,S. 1997. Fertility Transition in Zimbabwe: Determinants of Contraceptive Use and Method Choice. Population Studies, 51:173-189.

Gwebu,T.D. 2001. Rural Fertility Differentials in Southwestern Zimbabwe. African Population Studies.16:43-54.

Gwebu,T.D. 2000. Intra-rural Patterns, Determinants, and Policy Implications of Fertility Differentials: An Investigation of Communal Land Resettlement Lands of SouthWestern Zimbabwe. Union for African Population Studies,44:1-80.

Gwebu,T.D. 1991. Patterns of Planned Rural-Rural Population Redistribution in Zimbabwe and Emerging Development Issues. Etude de la Population Africaine .6:95112. 
Gwebu, T.D. 1990. A comparative Analysis of the Social Economic Impacts of Rural Resettlement in Matabeleland and Masvingo Provinces. ADF. Washington DC.

Hawthorn,G. 1970. The Sociology of Fertility. Collier-Macmillan Ltd. London.

Jain, A. 1985. The Impact of Development and Population Policies on Fertility in India. Studies in Family Planning,16:18t19198ps.journals.ac.za

Jones,H. 1990. Population Geography. Paul Chapman. London.

Kar,S.B. 1978. Consistency between Fertility Attitudes and behaviour: A Conceptual Model. Population Studies 51:173-189

Kokole O.H. 1994. The Politics of Fertility In Africa. in Finkle J.L. Macintosh, C.A. (eds.) The New Politics of Population. Population and Development Review, 20: 73-88.

Martin, T.C. 1995. Women's Education and Fertility: Results from 26 Demographic and Health Surveys. Studies in Family Planning 26: 187-202.

Poo Chang Tan and Nai Peng Tey. 1994. Do Fertility Intention's Predict Subsequent Behaviour? Evidence from Peninsular Malaysia. Studies in Family Planning. 25: 222231.

Population Reference Bureau. 2002.World Population Data Sheets 2002. Population Reference Bureau. NY.

Rogers,E.M. 1995. Diffusion of Innovations. The Free Press. New York.

Thomas,D.,Muvandi,I. 1994. Fertility Trends in Southern Africa: A Debate on the Demographic Transition in Southern Africa: Another Look at the Evidence from Botswana and Zimbabwe.Demography,31:185-207,217-227.

UNECA. 1990. Population Issues in Africa in the 1990's. African Population Newsletter. 59: 6.

UNECA. 1991. Population and AAF-SAP. African Population Newsletter. 60: 7. 